\title{
Subalternidade, representação e participação da comunidade LGBTQIAP+ no cenário político brasileiro
}

\section{Subalternity, representation and participation of the LGBTQIAP+ community in the brazilian political scenario}

\author{
Alberto Barreto Goerch ${ }^{1 *}$, Miguel Soares Silveira ${ }^{2}$, Everton Rodrigo Santos ${ }^{1}$, Gabriel Eidelwein \\ Silveira $^{3}$
}

\begin{abstract}
RESUMO
$\mathrm{O}$ artigo aqui estruturado apresenta-se em três partes distintas e entrelaçadas, a primeira debruça-se sobre a criação e trajetória do movimento "LGBT" e da emergência de um novo sujeito político como cerne de novas exigências políticas, a segunda, por sua vez, analisa e explica como se estabeleceu (e ainda se estabelece) a questão da subalternidade deste movimento e sua exclusão de debates politizados e decisórios comumente no Brasil e a terceira, estuda e observa como é engendrada a representação política brasileira de membros da comunidade LGBTQIAP+ e seus efeitos na elaboração de políticas públicas eficazes às minorias sexuais. Também propõe como finalidade primordial a análise da subalternidade e suas manifestações diversas pela comunidade LGBTQIA+, além de demonstrar como tal fenômeno se reflete no campo político, questionando acerca de sua representação e participação políticas. Traçando um breve histórico do Movimento LGBT, almeja-se entender como se consolida a posição desses grupos subalternos para, a partir daí, analisar, compreender e questionar a relevância da representação e participação política e social deste grupo considerado minoria sexual e se este apresenta detrimento aos direitos e causas heteronormativas no Brasil.
\end{abstract}

Palavras-chave: Movimento LGBTQIAP+; Representação política; Subalternidade;

\begin{abstract}
The article structured here is presented in three distinct and intertwined parts, the first deals with the creation and trajectory of the "LGBT" movement and the emergence of a new political subject as the core of new political demands, the second, in turn, analyzes and explains how the question of the subordination of this movement was established (and still is established) and its exclusion from politicized and decision-making debates commonly in Brazil and the third, studies and observes how the Brazilian political representation of members of the LGBTQIAP+ community is engendered and its effects on the design of effective public policies for sexual minorities. It also proposes as its primary purpose the analysis of subordination and its diverse manifestations by the LGBTQIAP+ community, in addition to demonstrating how this phenomenon is reflected in the political field, questioning about its political representation and participation. Tracing a brief history of the LGBT Movement, the aim is to understand how the position of these subordinate groups is consolidated in order to, from there, analyze, understand and question the relevance of the political and social representation and participation of this group considered to be a sexual minority and whether it presents detriment heteronormative rights and causes in Brazil.
\end{abstract}

\footnotetext{
${ }^{1}$ Universidade Feevale - FEEVALE

*E-mail: betogoerch@gmail.com

${ }^{2}$ Universidade Federal de Pelotas - UFPEL

${ }^{3}$ Universidade Federal do Piauí - UFPI
} 
Keywords: Movement LGBTQIAP+. Political representation. Subalternity.

\section{INTRODUÇÃO}

No período pós-redemocratização brasileiro, muito se observou (e questionou) uma tentativa de representação política de grupos subalternos que, a princípio, tomavam força e se articulavam para uma maior visibilidade estatal e política, tendo, a título de exemplo e também sendo o foco central deste estudo, a comunidade LGBTQIAP+ como integrante dessa sub-representação política. Embora distintos e até mesmo conflitantes, os termos e conceitos de "democracia e representação política" são bastante questionáveis quando se tenta legitimar, de forma infrutífera, um governo que represente o povo e as minorias sociais.

Em regimes intitulados democráticos, é cada vez mais perceptível e notória a super-representação de segmentos e interesses de grupos que legitimam instituições representativas liberais em detrimento de grupos excluídos e marginalizados através da representação política brasileira. Dentro dessas parcelas subalternas encontram-se mulheres, a população preta, o proletariado, os membros da comunidade LGBTQIAP+ que são tidos como desviantes da heterossexualidade compulsória dentre outros que não dispõem de instrumentos eficazes na luta pela democracia e representação, ficando à mercê de ocupar posições de poder, tanto pela dinâmica da exclusão social quanto pelos filtros institucionais que tendem a reproduzir as desigualdades na esfera pública e na política eleitoral.

É nesse contexto de subalternidade que se articula e nasce, nas décadas de 80 e 90, o Movimento LGBTQIAP+ (nomeado, pioneiramente, como Movimento Homossexual Brasileiro). De uma multidão atomizada, esta população passou a se organizar, elaborando uma visão de mundo própria, que deu sentido mais amplo aos seus problemas comuns, tornados reivindicação política. Isso significou a emergência dos LGBTQIAP $+{ }^{4}$ como grupo social destacado no interior da sociedade.

Esta polarização do movimento com seus interesses e reivindicações põe em análise, de um lado, a demanda imediata de políticas públicas e direitos destinados à minoria sexual e, de outro, a necessidade e a expectativa de uma reconstrução social mais

\footnotetext{
${ }^{4}$ Usa-se a sigla supracitada por questão de inclusão e visibilidade, de modo que tenta abarcar de forma mais igualitária a identidade de gênero e orientação sexual.
} 
ampla e sólida. Nesse diapasão de entender e tentar explicar tal dicotomia, o presente estudo entende que a condição de subalternidade e sua possível superação só poderá se efetivar se forem modificadas ambas as demandas, tanto de conquistas de direitos quanto de reconfiguração da crítica estrutural sexual.

Dessa forma, o referido grupo subalterno, em seu processo de tentar se constituir como um sujeito político atuante em centros decisórios, começa a atuar e participar de espaços na esfera política de modo a reproduzir sua subalternidade por meio de outros instrumentos, mas, dessa vez, não mais pela exclusão social ou até mesmo falta de visibilidade, mas na tentativa de participar, fazer parcerias e ser reconhecido como interlocutor político.

Tendo como base esse contexto apresentado acima, o artigo aqui estruturado apresenta-se em três partes distintas e entrelaçadas, além desta introdução e das considerações finais: a primeira debruça-se sobre a criação e trajetória do movimento "LGBT" e da emergência de um novo sujeito político como cerne de novas exigências políticas; a segunda, por sua vez, analisa e explica como se estabeleceu (e ainda se estabelece) a questão da subalternidade deste movimento e sua exclusão de debates politizados e decisórios comumente no Brasil; a terceira, por fim, estuda e observa como é engendrada a representação política brasileira de membros da comunidade LGBTQIAP+ e seus efeitos na elaboração de políticas públicas eficazes às minorias sexuais. Sendo assim, ao final, há a síntese de todas as partes elencadas acima e possíveis conclusões (não exaurientes) das discussões extraídas do confronto entre a subalternidade sexual e a representação política.

\section{A CONSTRUÇÃO DO MOVIMENTO “LGBT" E O SURGIMENTO DE UM NOVO SUJEITO POLÍTICO}

Com a onda de novos atores sociais e a efervescência cultural que o mundo vivia a partir do final do século XX, houve uma expansão das questões políticas na sociedade em decorrência de uma ressignificação dos limites postos entre a esfera pública e privada, de modo que não era apenas nos movimentos sociais o epicentro das principais manifestações e contestações culturais, mas também um meio de representar tais anseios na arena política. Esses movimentos contemporâneos, assim, "apontaram para um reconhecimento de aspectos do político em esferas da vida social ainda não politizadas" e com o avanço da passagem de século a chamada "participação movimentalista" se 
tornou uma forma cada vez mais comum de exercer a atuação política (PRADO e MACHADO, 2014, p. 63) ${ }^{5}$.

No Brasil, portanto, os movimentos sociais eram tidos como carregados de um forte viés sociocultural, político e de cidadania, aduzindo a manifesta ideia de que eles seriam os responsáveis pela efetiva transformação social da população brasileira e do Estado nacional. Enaltece Dagnino:

Em primeiro lugar, o fato de que ela [cidadania] deriva e, portanto, está intrinsecamente ligada à experiência concreta dos movimentos sociais, tanto os de tipo urbano - e aqui é interessante anotar como cidadania se entrelaça com o acesso à cidade - quanto os movimentos de mulheres, negros, homossexuais, ecológicos etc. $\mathrm{Na}$ organização desses movimentos sociais, a luta por direitos - tanto o direito à igualdade como o direito à diferença - constituiu a base fundamental para a emergência de uma nova noção de cidadania (DAGNINO. 2002, p. 104).

Assim, Doimo (1995), Gohn (2001), Dagnino, (2002) e Soares do Bem (2006) propõem uma interpretação da trajetória dos movimentos no Brasil principalmente pela ressignificação que eles passaram a ter: não mais preocupados com demandas materiais, mas com reivindicações não-materiais, de identidade, de direitos, da necessidade de renovação das formas de vida política. E compartilham do entendimento de que os movimentos contribuíram para uma ampliação da participação social na vida política nacional, ocorrendo mudanças na formulação de políticas públicas e na adoção de um novo "fazer político" (MACHADO e PRADO, 2005, p. 37).

É a partir do fim da ditadura que se fundam canais institucionais de exercício pleno da cidadania e de participação pública, possibilitando, portanto, uma melhor atuação e um maior trânsito do Estado com a sociedade civil, em que avanços significativos tomam força na conjuntura política brasileira para uma construção de um debate político mais elaborado, fundamentado, inclusivo e democrático. Anteriormente constituídos a partir da ideia de representação espontânea e de oposição ao regime fechado, os grupos organizados dos movimentos sociais, em geral, tiveram que se adaptar às mudanças impostas pela redemocratização e a Constituição Federal de 1988 (CARDOSO, 2004). E é a partir desse contexto histórico que a participação social tomava um maior destaque, sem qualquer precedente de tamanho tão significativo quanto aquele.

\footnotetext{
5 Isso se explica porque "the social movement sector has grown so much because western societies have become less hegemonic", ou pelo fato de que "contentious collective actions can be remarkably effective, provided that the right ingredients are in place" (Klandermans, 2003, p. 672).
} 
Especificamente ao surgimento propriamente do movimento aqui no Brasil, em meados de 1978, a maioria expressiva da literatura aponta para a fundação do Jornal Lampião da Esquina e a articulação do Grupo SOMOS (além de grupos homossexuais que se criavam durante a ditadura), sendo, assim, o ponto de efusão e da gênese de um movimento que se organizava de forma coletiva nunca existente antigamente, buscando reconhecimento de seus direitos perante a sociedade heteronormativa estrutural. De acordo com James Green (2000),

[...] Em 1978, um pequeno grupo de intelectuais do Rio de Janeiro e de São Paulo fundou o Lampião da Esquina, um tablóide mensal de ampla circulação dirigido ao público gay. Muitos meses depois, um grupo de homens em São Paulo formou o SOMOS, a primeira organização pelos direitos gays do país (2000, p. 395).

As marcas da sua primeira onda de politização foram esforços no sentido de afirmar uma identidade homossexual, na medida em que uma parte da militância buscava uma maior integração social e outra, em especial as feministas lésbicas, priorizavam justamente a construção de uma comunidade gay autônoma (SILVA, 2008). Entretanto, por uma outra visão cultural, esses atores eram marginalizados a uma realidade social que lhes era negada, sendo, inevitavelmente, forçados a viver na margem subalterna societária, em posições de sigilo e segredo, no subterrâneo, sem qualquer resquício de direito legítimo e dignidade humana, sem acessos efetivos as esferas de poderes decisórios.

Como vivia-se em um período profundamente hostil e antidemocrático, a veiculação do Lampião da Esquina passou a ser alvo do governo e de muitos militares à época, visto que a homossexualidade era tida como subversiva e rejeitada.

[O jornal] Lampião se diferenciava também no modo como abordava a homossexualidade. O jornal procurava oferecer um tratamento que combatesse a imagem dos homossexuais como criaturas destroçadas por causa de seu desejo, incapazes de realização pessoal e com tendências a rejeitar a própria sexualidade. Mas não fazia isso de modo a concentrar-se exclusivamente nos homossexuais e, sim, apresentando-os como uma entre as várias minorias oprimidas que tinham direito à voz. O jornal se propunha a "sair do gueto" e ser um veículo pluralista aberto a diferentes pontos de vista sobre diferentes questões minoritárias. (SIMÕES e FACCHINI, 2009, pp. 85-86).

A articulação e o desenrolar do movimento modificou prioridades e estratégias da luta social, pautando-a na promoção de Direitos Humanos como uma alternativa à (re)construção sociocultural que estava sendo desencadeada, propulsionando olhares 
mais críticos para a sociedade. Para que isso acontecesse, algumas organizações que levantavam esta bandeira merecem destaque, a saber, o "Grupo Gay da Bahia e o Triângulo Rosa do Rio de Janeiro", bem como o grupo "Libertos", que, de forma honrosa, excluíram a homossexualidade do código de doenças mentais, no ano de 1990.

Dessa forma, percebemos que o movimento LGBT, desde seu início, dialogava com as questões políticas existentes no Brasil, tanto que Green (2003) e Okita (2015) corroboram esta informação, afirmando que os gays e as lésbicas estiveram presentes nas lutas pelas liberdades políticas e nas lutas pelos direitos econômicos, sociais e culturais, quando diferentes segmentos resolvem construir e fundar um partido de esquerda, a exemplo do Partido dos Trabalhadores (PT), de modo que participaram das lutas gerais no processo da transição política a partir de 1974 nas lutas pela Anistia e por direitos sociais, como na caminhada do dia $1^{\circ}$ de maio de 1980 , na greve do ABC.

Nessa conjuntura de ausência de garantias de direitos e pelo avanço da HIV/AIDS (estigmatizada como o "câncer gay"), formaram-se organizações nãogovernamentais que colaborou para uma certa institucionalização do movimento social.

Imediatamente, e de forma indireta, a epidemia de HIV/AIDS contribuiu para alavancar o nível de preconceito e marginalização do povo homossexual, gerando, com isso, maior exclusão do grupo à participação política e popular. Tal fator, aliado à heteronormatividade ${ }^{6}$ estrutural, facilitou ainda mais a subalternidade desta minoria para uma sub-representação e até mesmo invisibilidade em muitos casos.

Contudo, com a ajuda de órgão internacionais, a exemplo a OMS (Organização Mundial da Saúde), a sexualidade passou a integrar de forma mais evidente o debate político com o intuito de fomentar uma política nacional de prevenção à doença pelo governo federal. O movimento, então, tornou-se parceiro do Estado. Desta forma, o movimento LGBT se utilizou do que a autora Maria da Glória Gohn (2010), chama de "oportunidade política" e, assim, utilizou os recursos destinados ao combate da AIDS para fortalecer a luta pelos direitos humanos dos "LGBTQIAP+" (2010, p. 107).

De forma que o sujeito político do movimento LGBT também passou a se tornar mais complexo, caminhando em direção a uma heterogeneidade dos seus próprios atores

\footnotetext{
6 A heteronormatividade visa regular e normatizar modos de ser e de viver os desejos corporais e a sexualidade de acordo com o que está socialmente estabelecido para as pessoas, numa perspectiva biologicista e determinista, há duas - e apenas duas - possibilidades de locação das pessoas quanto à anatomia sexual humana, ou seja, feminino/fêmea ou masculino/macho (MEYER, Dagmar Elisabeth Estermann; PETRY, Analídia Rodolpho, 2011).
} 
com diversas reivindicações e demandas específicas (FACCHINI e FRANÇA, 2009), a construção do movimento LGBT como sujeito deve ser analisada no marco da construção dessa população à condição de "massa para si". Sendo assim, a dimensão da subalternidade começa a se situar no campo da ação política imediata, da tática e da estratégia, na arena das lutas e embates hegemônicos.

Desse modo, tal reconhecimento do movimento encontra na relação com o Estado um problema central: de um lado, há sua identificação enquanto interlocutor político legítimo; de outro, o Estado mostra-se como um espaço de organização e articulação legitimada para a atuação do próprio movimento em busca de seus direitos e garantias. A estrutura participativa atua como espaço de organização do consenso da população LGBTQIAP+ junto ao governo. Logo, todas as manifestações e desejos de direitos políticos, democráticos e estruturadores se canalizam por meio dessa organização que vinha se formando dentro da ação estatal.

E é exatamente nesse fluxo e trânsito da sociedade civil/movimento "LGBT" com o Estado que as lideranças sociais se alternam em militantes e gestoras da política estatal, ao passo que a insatisfação deste recorte social se minimiza no interior dessa estrutura pseudo-participativa que preza, acima de tudo, pela igualdade social dos cidadãos brasileiros. Mesmo com crises e desavenças, esta relação mencionada se manteve até mais ou menos a reeleição da presidenta Dilma Rousseff em 2014, ocasionando, a partir daí uma dependência do movimento ao Estado de forma profunda.

Com a formação do movimento enquanto sujeito para si, questiona-se, neste presente estudo, se tal sujeito pode ser enquadrado como hegemônico para disputar a arena política e cultural do Brasil ou se apenas é uma nova forma de representação da subalternidade que permeia a sociedade patriarcal e discriminatória como a brasileira. Avalia-se, também, se a relação Movimento X Estado, por meio da participação em espaços institucionais que atuam como aparelhos hegemônicos, pode ser legítima; se há, efetivamente, uma relação de hegemonia ou subalternidade. 


\section{SUPERAÇÃO DA SUBALTERNIDADE?}

No Caderno 25 Gramsci apresenta algumas notas que ajudam a compreender o significado com que utiliza a noção de subalternidade. Numa rápida e instigante afirmação, é dito que "para uma elite social, os elementos dos grupos subalternos têm sempre algo de bárbaro ou patológico" (GRAMSCI, 2002, p. 131). Já no §2 do mesmo caderno é apontada como "característica dos subalternos sua desagregação" (GRAMSCI, 2002, p. 135). Assim, mesmo que haja certa tendência à unificação, esta sofre a interferência dos grupos dominantes, o que leva Gramsci (2002) a fazer um alerta metodológico, falando sobre a importância de se analisar as iniciativas autônomas destes grupos, uma vez que raras e significativas.

De acordo com Simionatto (2009): "No âmbito da sociedade civil, a classe dominante, através do uso do poder por meios não violentos, contribui para reforçar o conformismo, apostando na desestruturação das lutas das classes subalternas, reduzindoas a interesses meramente econômico-corporativos" (2009, p. 43). Neste sentido o alargamento do conceito de subalternidade, no pensamento de Gramsci, tenta recuperar os processos de expropriação a que os subalternos foram submetidos (PELÚCIO, 2012).

Contudo, é no $\S 6^{\circ}$ que se questiona e problematiza o cerne do problema da subalternidade, em que aduz:

A unidade histórica fundamental, por seu caráter concreto, é o resultado das relações orgânicas entre Estado ou sociedade política e "sociedade civil". As classes subalternas, por definição, não são unificadas e não podem se unificar enquanto não puderem se tornar "Estado": sua história, portanto, está entrelaçada à da sociedade civil, é uma função "desagregada" e descontínua da história da sociedade civil (GRAMSCI, 2002, pp. 139-140).

O processo de inserção do subalterno no ramo estatal se concretiza no sentido de tentar balancear as demandas jurídicas e políticas dos movimentos sociais. A grande discussão aqui é a presença de inúmeras diferenças por parte da desigualdade jurídicopolítica dentro do Estado e a produção passiva, através de meios pacíficos e não violentos, para a manutenção dos interesses dos subalternos em decorrência da sociedade civil. Nesse sentido o objetivo dos Estudos Subalternos é relatar o que foi ocultado pela historiografia oficial (LINO, 2015).

A disputa, então, contra a subordinação é pela conquista da autonomia. Isso não reduz o conflito ao choque contra a coerção dos dominantes, mas o situa também no 
terreno da sociedade civil, da luta ideológica, ou ainda da tática da guerra de posição (BUTTIGIEG, 2009, p. 828).

Tais concepções vão ao encontro do problema de se construir uma identidade em oposição àquela imposta, visto que condiz com a afirmação de uma identidade que revele a relação de poder e que constrói a subordinação ${ }^{7}$, podendo, portanto, ser elevada à arena política tornando-se "partido". Gramsci se colocava já o problema da unificação das classes subalternas da Itália como uma contribuição à unificação do gênero humano (DEL ROIO, 2007).

A ação de estigmatização (etiquetamento social) ${ }^{8}$ que sofrem os subalternos, e que é imposto e cobrado dos grupos dominantes hegemônicos, implica no silenciamento e na contrariedade de suas ações. Nesse processo, foi aberta uma nova série de "possíveis futuros". De modo significativo, "os temas de gênero, religião e casta foram abertos à discussão desde o ponto de vista subalterno, levantando muitas questões políticas ‘desconfortáveis' (GÓES, 2016, p. 99). Exatamente nesse ponto é que se coloca “em xeque" a questão da nova hegemonia do sujeito político, qual seja, o sujeito LGBTQIAP+ que faz parte do Estado.

A busca pela universalidade e pela expansão no campo político frustra-se em combate com a subordinação e a subalternidade que é posto o movimento de membros da comunidade sexual desviante do padrão heteronormativo. Porém, na ideia de Gramsci (2002), a luta contra a posição de subalternidade é também uma atividade de cunho político-prática e não restritivamente cultural.

O entendimento que se tem do que é e como se comporta o grupo subalterno faz correlação com segmentos mais empobrecidos, explorados e discriminados da sociedade civil, numa referência evidentemente estrutural (SÁ e ARRAZOLA, 2015). Logo,

A hegemonia não exprime apenas uma ideologia, ela vai além, podendo ser caracterizada como a habilidade de controle, do poder da classe dominante e dirigente, ou seja, do controle social. Desta forma, podese dizer que o partido é um elemento importante para a hegemonia da

\footnotetext{
7 Ainda no Caderno 25, Gramsci comenta a situação dos escravos na Roma antiga, num episódio no qual um senador se colocou contrário à identificação dos escravos no espaço público por meio do uso de roupas específicas "por temor de que eles se tornassem perigosos, ao se darem conta de seu grande número" (GRAMSCI, 2002, p. 142).

8 Teoria usada nas Ciências Penais e Criminológicas que levantam hipóteses relativas aos critérios que determinam a seleção e estigmatização de certos indivíduos, bem como quais consequências essa estigmatização poderia trazer levando-se em conta uma carreira criminosa (DIAS e ANDRADE, 1997). Tal teoria pode ser relacionada à estigmatização sofrida pelos LGBTQIAP+ na sociedade em geral, ao passo que ocupa lugares de marginalização e subalternidade.
} 
classe operária, pois funciona como unificador de pensamentos e ações, "como formador de "de uma vontade coletiva; o partido é a primeira célula onde se contém germes de vontade coletiva que tendem a tornarse universais e totais" [...] no sentido que no partido já existe uma visão total da sociedade" (GRAMSCI apud GRUPPI, 1980, p. 74).

Tal entendimento, aqui, é estendido à população LGBTQIAP+, já que esta população tem sua identidade ditada e determinada de forma externa por meio de instrumentos que estão inseridos e trabalham no terreno das superestruturas políticas e ideológicas, incluindo-se aí a moral, a religiosidade, a ciência etc. Pragmaticamente, refere-se a um conjunto de cidadãos que é alvo de relações de poder e subordinação no âmbito político-cultural.

Todo o desenrolar da retirada de oportunidades que sofreu (e ainda sofre) a comunidade LGBTQIAP+ acarretou em um silenciamento indireto de seus valores e objetivos e a estigmatização já supracitada. E é justamente por analisar tal situação que a subalternidade vem à tona no tocante ao referencial político deste grupo:

Nesse cenário, determinado pela política dos governos em questão, reside o problema da relação do grupo subalterno com o bloco dirigente. O modo de inserção nos espaços criados, as formas de relação com os atores da sociedade política, a relação do movimento com suas bases e a visão de mundo, produzida e difundida neste processo, devem ser analisadas sob o problema da hegemonia e da manutenção da condição subalterna (ALVES, 2016, p. 142).

Por ser a política e o governo uma dimensão ocupada por heterossexuais e seus aliados, a demanda de direitos e garantias homo/trans acaba por ser secundária e relegada ao plano da sub-representação e afastamento político-social. Ou seja, a dominância de grupos subalternos compreende a imposição intelectual e moral de um grupo sobre o outro, havendo, com efeito disso, a coerção sobre seus adversários.

As instituições e organizações que regem o Estado podem ser tidas como extremamente articuladas para impedir o acesso de grupos desprivilegiados nos processos de decisão e inclusão, o que evidencia o forte descaso com a dignidade dos mesmos. Assim, "os sujeitos seriam constituídos como forças "sociais-políticas" que se determinariam num contexto de relações relativamente independentes do processo de produção imediato e com base na elaboração crítica das próprias funções" (GALASTRI, 2014, p. 40).

Essa exclusão, por sua vez, pode ser interpretada e entendida de forma a se pensar que até mesmo a linguagem, a formalidade e as oportunidades para os subalternos se tornam escassas e dúbias quando contrapostas com o grupo dominante que detém o 
monopólio estatal. Gramsci (2002) modifica a abordagem da categoria classe social para esclarecer as novas dimensões da luta de classes.

Se, a partir de Marx, as classes sociais se definem pela participação no processo produtivo, a introdução da noção de subalterno não nega que a delimitação do significado se encontra no processo de produção material, mas permite relacionar o econômico, o político e o ideológico, para explicitar, na unidade dialética dessas instâncias, as relações de dominação (SCHLESENER, 2016). Sendo assim, para Gramsci (2002), os grupos subalternos possuem condições de dominados no contexto de uma hegemonia que lhes é exterior.

A partir de tais estudos e observações, questiona-se, como ideia central deste estudo, qual a condição do movimento (e do grupo) LGBTQIAP+ na representação política brasileira e no ramo governamental como um todo, pois, de um lado, para suprir a questão da subalternidade, o grupo deve estar equiparado aos outros grupos que fazem parte das lutas hegemônicas e ocupam posições de poder dentro de um Estado; por outro, questiona-se até que ponto essa formação do sujeito político LGBTQIAP+ consegue travar lutas igualitárias e democráticas dentro de um sistema que foi estruturado para marginalizar e estigmatizar pessoas que fossem desviantes da norma padrão de sexo e gênero.

Dessa forma, contesta-se se realmente foi superada a circunstância de subalternidade deste referido grupo social ou se apenas é mascarada por pseudorepresentações políticas hegemônicas, que são permeadas por convicções de luta de classes do dominante contra o dominado, a exemplo da contribuição de Marx.

A próxima seção analisa e revela como se perfectibiliza essa representação política da comunidade LGBTQIAP+ no governo brasileiro e qual a consequência disso para a conquista de interesses e garantias da mesma, entendendo, com isso, como a subalternidade afeta diretamente nas posições que ocupam frente ao Estado e se a representação dela é de forma legítima e plena.

\section{A REPRESENTAÇÃO POLÍTICA DA COMUNIDADE LGBTQIAP+ BRASILEIRA}

A representação política surge, primordialmente, como meio alternativo à impossibilidade de reunir, na sociedade de massas, todos os cidadãos e cidadãs para 
debater e decidir sobre os diferentes interesses que circulam nas nações e sociedades. A representação é, em síntese, tornar presente o que está ausente (PITKIN, 1967).

Segundo Pitkin (1967), Hobbes diferenciou os sujeitos em naturais e artificiais. As pessoas naturais são aquelas que agem diretamente por si, já as pessoas artificiais atuam em nome de outras, das pessoas naturais. A separação entre pessoas naturais e artificiais é a base para a ideia moderna de representados e representantes atores da representação política. Com isso, é dada certa autonomia aos representantes agirem em nome dos representados dentro de espaços decisórios e politizados.

Contudo, como tem acontecido em diversos países democráticos ocidentais, está se criando um grande distanciamento dos representantes de seus representados quando se verifica uma atitude contraditória dos mandatários em relação aos desejos e aspirações do público eleitor.

Tal distanciamento tem acarretado em profundas crises nos regimes democráticos de governo, que se expressam em diferentes manifestações populares que lutam por direitos e não só pela melhoria dos sistemas representativos, bem como de uma maior participação política direta de todas as decisões que efetivamente atingem a população.

Pitkin (1967) aposta na forma de representação substantiva, visto que a ênfase que aqui se faz não é em quem se representa, mas, sim, nos pensamentos e ideologias daqueles que são representados na esfera pública. Ou seja, é a partir daí que os representados conseguirão construir um vínculo afetivo com seus representantes e avaliar a qualidade daquela representação de maneira abrangente.

Porém, tal teoria esbarra nos ideais feministas que vão questionar a ausência e a exclusão de determinados sujeitos e agendas no exercício representativo. É desse entendimento feminista (e da crescente e assustadora exclusão das mulheres nos ramos estatais) que Anne Phillips (1995) defende uma representação como política de presença, na medida em que apenas o sufrágio feminino não contemplaria quase nada para a inclusão das mulheres e a promoção de igualdade das mesmas nos centros de poder e decisão.

Mesmo após a conquista do direito ao voto às mulheres, a representação das mesmas ainda permanece muito baixa e invisível, ao passo que, para tentar corrigir tais imperfeições, com a ajuda da luta feminista, foram editadas legislações de cotas para 
mulheres na política, numa tentativa (infeliz) de tentar igualar formalmente as relações estruturais entre homens e mulheres.

Reconhecendo as contradições das políticas de cotas, Phillips não propõe uma substituição da política de ideias pela política de presença, mas sim uma combinação entre as duas, de modo a qualificar a representação e torná-la mais justa. Nesse sentido, a visão de responsividade permanece mantida. É da bagagem desse estudo que Phillips, após, apresenta a ideia de perspectivas sociais, de modo a fortalecer a política de presença através da valorização e reconhecimento de experiências que posicionam as sujeitas.

Trazendo tal análise para a população LGBTQIAP+, muitos problemas e perigos se insurgem da mesma forma como ocorrem com as mulheres: a discriminação, a agenda dos direitos sexuais tida como específica e não universal, as questões que diriam respeito à esfera íntima (portanto, privada) e não pública, o descrédito, a desqualificação, a incapacidade, as performances identitárias inadequadas para a arena política ou até mesmo a tentativa de instaurar uma "ditadura gay" em que os heterossexuais terão de suportar a "normalização" de condutas promíscuas, inadequadas, desviantes ou pecaminosas.

Sendo assim, ações afirmativas destinadas a este recorte social mostram-se mais complexas pelo terreno mais arenoso que tais lutas de gênero e sexualidades se apresentam. É quase que contraditório pensar em uma maior proteção legislativa e democrática para o segmento sexual quando, para isso, precisa-se de parlamentares que defendam tal causa e legitimem seus discursos em um espaço marcado pelo conservadorismo e patriarcalismo.

Não há, na esfera da representação, local de inserção destes indivíduos, pois até mesmo os partidos políticos e as candidaturas eleitorais se tornam difíceis por serem de pessoas subalternas à política e representação. Ou melhor, não há essa troca entre um grupo ligado à subalternidade com uma expansão pública e cultural dos ideais de identidade de gênero e sexualidade.

Exemplos mais plausíveis desse ensaio de proximidade poderiam ser campanhas de recrutamento partidário, estímulo a candidaturas e promoção de debates sobre esse tema em diferentes setores da sociedade.

A desigualdade política envolvendo os integrantes do grupo subalterno LGBTQIAP+ não consegue vislumbrar na arena governamental possibilidades concretas de êxito eleitoral, tampouco transformações significativas e representativas facilmente 
alcançáveis, já que o Congresso e todo o sistema brasileiro evidencia a marginalização de minorias.

Esse foi um dos motivos que levou o movimento minoritário a criar uma categoria de "aliados" ou "simpatizantes" nos seus cálculos eleitorais, uma vez que as decisões são transferidas para quadros políticos heterossexuais para que, ao menos, tentem combater mais diretamente a árdua disputa eleitoral. E a subalternidade aqui se faz de forma indireta e tortuosa por ter no sistema sua principal causa e consequência. Flávia Biroli (2014) comenta: “embora no nível do indivíduo o não surgimento da ambição política reflita apenas a variação das inclinações pessoais, quando afeta todo um grupo social se torna um índice poderoso da desigualdade política” (2014, pp. 664-665).

Em outras palavras, é comum que determinadas pessoas não ambicionem a política como uma carreira ou exercício da cidadania, mas não é normal que segmentos constituídos por características comuns não estejam presentes nas esferas de poder (BIROLI, 2010).

Acerca do problema da representação deve-se ressaltar a insuficiência de mecanismos de controle pelos representados, dependendo única e exclusivamente da boa vontade dos representantes: "os mecanismos que permitem que os representados desautorizem o representante caso desaprovem sua atuação não foram criados ainda.

O vínculo entre representante e representado ainda depende da boa vontade do primeiro" (TEIXEIRA, SOUZA, LIMA, 2012, p. 23). Coloca-se, assim, um grande empecilho na determinação da legitimidade dos representantes, no qual sugere que o governo tenha função essencial na definição de quem pode exercer a representação, de modo que diz respeito à forma que se concebe a autonomia dos movimentos que participam. Para Teixeira, Souza e Lima (2012) “o que se observa é que a força de autorização para a representação nos espaços participativos nacionais estudados não emana dos representados e sim do órgão que institui o espaço ou do reconhecimento por organizações que já estão legitimadas para atuação naquela instância" (TEIXEIRA, SOUZA, LIMA, 2012, p. 41).

Deste modo, há de ser ressaltado que houve expansão no cenário dos espaços institucionais reservados para a participação da sociedade civil, contudo, ao se observar de forma pormenorizada, tal expansão sugere muitas contradições no campo da representação política. Tendo o movimento LGBTQIAP+ uma relação com o Estado, percebe-se que a mesma não garante uma efetiva presença de qualquer que seja contrário 
à heteronormatividade, ao passo que o movimento enfraquece sua autonomia, agravando, ainda, quando as políticas públicas destinadas à igualdade de gênero e sexualidade não possuem uma concreta e efetiva realização.

Entendendo e analisando esse cenário, fica evidente e fácil a compreensão da exclusão dos LGBTQIAP+ na arena política e o estrangulamento da participação da sociedade civil. Primeiramente porque é árdua a tarefa de percepção de que os gêneros e as sexualidades possuem posições pré-estabelecidas na sociedade em geral, já que o brasileiro vive em um contexto de educação defasado e deficitário. Ou seja, falta a compreensão de que a sexualidade e suas ramificações são mais do que meras características humanas, são também marcadores sociais que delimitam valores, interesses e direitos fundamentais, de modo que aquele que é tido como "não-padrão" é inserido no povo subalterno da representação, participação política e até mesmo da construção de identidades sociais.

Dessa forma, politizar a sexualidade e o gênero, é uma barreira extremamente complexa a ser ultrapassada, pois não há uma solidificação das políticas públicas eficazes no combate à discriminação e também porque o sistema político como um todo marginaliza a presença de minorias sociais, seja pelo fato da falta de representantes ou pelo fato de seus representantes não suprirem suas necessidades e coligarem com partidos hegemônicos e regidos por heterossexuais que secundarizam as demandas sexuais.

Mesmo que haja, de certa forma, algumas barreiras à participação política, como a entrada no Movimento ou a presença em fóruns de participação social (com o tema "LGBTQIAP+" ou outros), a ambição política é desestimulada pelo próprio campo político com suas regras, dinâmicas próprias, recursos exigidos e culturas masculinizadas/cis-heterossexualizadas incrustadas nas instituições políticas.

O primeiro desafio é a entrada nos partidos políticos, também frágeis democraticamente e dirigidos por homens cis-heterossexuais. Além disso, os partidos apresentam em seus programas e projetos conteúdos de base material, priorizando a luta (ou a dominação, no caso do empresariado, latifundiários e banqueiros) de classe, entendida como a questão humana primordial que define as nossas vidas.

$\mathrm{Na}$ disputa eleitoral, os partidos tendem a apostar em candidaturas com mais chances de vitória e, nessa sociedade padronizada, homens brancos cis-heterossexuais têm mais vantagens e apelo junto ao eleitorado já que a eles é atribuído o papel de discutir os interesses públicos que serviriam a todos e todas, diferentemente de mulheres e 
LGBTQIAP+. Uma candidatura que apresente a defesa dos direitos dessa minoria sexual tende a atrair bem menos eleitores do que candidaturas que defendem pautas e agendas mais amplas como a da educação, da saúde ou da segurança. Ou pautas e segmentos que gozam de mais solidariedade social como a das crianças e adolescentes, pessoas com deficiência ou idosas.

A agenda política LGBTQIAP+, em um contexto violento como o brasileiro, não representa um capital político (BOURDIEU, 2000) substantivo e interessante a postulantes a cargos públicos. Por isso, é comum vermos candidatos e figuras políticas LGBTQIAP+ defensivamente afirmando que a sua atuação e a sua representação ultrapassam os limites da própria agenda de seus interesses e se estende para outras causas.

Uma causa bem atentatória à dignidade da comunidade é o temor de ser ofendido (a) publicamente em virtude de sua identidade de gênero e orientação sexual, bem como a concepção do acesso desigual de recurso, obstaculizando a presença da diversidade sexual no palanque político.

A exclusão educacional e mercadológica dificulta a obtenção de recursos econômicos, elemento primordial na disputa eleitoral, ao passo que culturalmente e estruturalmente o LGBTQIAP+ nunca, de fato, tornou-se sujeito político que fosse equiparado hegemonicamente com as classes dominantes da política nacional. $\mathrm{O}$ integrante da comunidade, além de complexidades econômicas, precisa enfrentar outros obstáculos na luta pela obtenção de prestígio público e participação.

A partir do entendimento firmado acima, mesmo que sejam elaboradas política públicas e o sistema político seja reformado, os grupos subalternos ainda não farão parte completamente de um problema estatal, pelo contrário, isso só reforçará a exclusão dos LGBTQIAP+ se não houver transformação e superação social fora do ramo da política. A estrutura do capitalismo liberal e da sociedade patriarcal e sexista impedirá o acesso de grupos desprivilegiados no poder, tentando mascarar a tal da igualdade como superada por meio de políticas públicas destinadas a esta minoria.

Spivak (2010), quando escreve "Pode o subalterno falar? ”, enfoca o subalterno não como sujeito marginalizado, mas como proletariado inserido no capitalismo global, as camadas mais baixas da sociedade constituídas pelos modos específicos de exclusão dos mercados, da representação política e legal, e da possibilidade de se tornarem 
membros plenos no estrato social dominante, como poderia agenciar sua fala? Como poderia articular poder, desejo e interesse?

A violência epistêmica acaba por ser perpetuada pelo intelectualismo que julga poder falar em nome do subalterno e que funciona como cúmplice do imperialismo, reproduzindo as estruturas de poder e de opressão ${ }^{9}$. Dessa forma, a autora afirma que a condição de subalternidade é a condição do silenciamento, ao passo que o subalterno necessariamente requer um representante por sua própria condição de silenciado.

Por um lado, observa-se a divisão internacional entre a sociedade capitalista regida pela lei imperialista e, por outro, a impossibilidade de representação daqueles que estão à margem ou centros silenciados (FIGUEIREDO, 2018). Sendo assim, tornar conhecida a condição de subalternidade ainda não é capaz de tirar-se da mesma, porém expor isto abre espaço para que novas análises e crítica sejam feitas sobre a dominação hegemônica ocidental/colonial e masculina.

Pelo exposto, nota-se que o estudo sobre a subalternidade e a representação política oferecem não só uma nova forma de produção autocrítica acadêmica, mas, também, conduzem à possibilidade de uma nova forma de conceber o projeto de partidos políticos em condições de globalização e pós-modernidade, uma vez que esses grupos em sua essência compartilham os ideais de mudança social e cultural.

\section{CONCLUSÃO}

É evidente que as lutas travadas até aqui para uma maior representatividade e participação LGBTQIAP+ foram extremamente positivas e válidas. Contudo, ao analisar um cenário de exploração e rejeição que se alastra há séculos, muito pouco se construiu no sentido de retirar os subalternos da condição de subalternidade de fato.

As tentativas de aumento da visibilidade da agenda da diversidade sexual e de gênero na esfera pública ainda suscita muitas reações contrárias por conservadores e fundamentalistas. É difícil e complexo, hoje, pensar que um grupo sempre vítima da subalternidade e marginalização pode concorrer politicamente com a mesma paridade de armas (nos campos decisórios) com a governança dominante desde a criação do Estado brasileiro.

\footnotetext{
${ }^{9}$ Resenha elaborada por Isabela Gaglianone em que tenta explicar a crítica feita por Spivak ao tratar do tema da subalternidade.
} 
Em nenhum momento histórico, principalmente pela pressão dos movimentos sociais, a ausência de gays, lésbicas, bissexuais, travestis, transexuais, intersexos, assexuais e qualquer pessoa que não integre a classe dominante heterossexual incidiu tanto no que diz respeito à falta de representação política tradicional, já que, no concernente ao desenho institucional brasileiro, é no Congresso que muitos direitos são votados e garantidos à população. Porém, é nesse mesmo lugar que é impedido o acesso de LGBTQIAP+ para que se façam ouvidos e considerados, pois as posições de poder no Brasil são dominadas por homens cis-heterossexuais em detrimento de toda uma diversidade de sujeitos, pensamentos e interesses.

O presente artigo, assim, buscou evidenciar como se perfectibiliza a condição da sub-representação de grupos subalternos e como tal fenômeno reflete na política nacional e na garantia de direitos. A aniquilação da produção de desejo e ambição política entre sujeitos e sujeitas vulneráveis que, em face das assimetrias e iniquidades, não se veem possibilitados a disputar espaços de poder formais acaba por invalidar o discurso de democracia e representação das minorias num ambiente desigual e marcado por violências.

É uma afronta às estruturas de poder, do ponto de vista da desigualdade econômica, mas também uma afronta subjetiva que visa reforçar os lugares inferiores de determinados grupos e coletivos. Talvez isto se explique pelo fato de que não existem condições suficientes para a democracia, à medida que a representação política nos canais formais do poder público - representado em suas estruturas parlamentares - é um monopólio dos partidos. Por isso que tal conjuntura tende a se embaraçar com uma crise de representação e participação civis.

Cabe salientar que o estudo dessa pesquisa não implica em uma limitação no seu desenvolvimento, pois ainda há muito o que se aprender e desconstruir acerca do Movimento e sua relação com o Estado, bem como a intenção é apenas construir uma crítica para que novos modos de pesquisa sejam feitos com o intuito de poder analisar e talvez até explicar tais situações trazidas ao longo do texto.

\section{REFERÊNCIAS}

ALVES, Douglas Santos. Movimento LGBT, Participação Política e Hegemonia / Tese de Doutorado/ UFRGS de Douglas Santos Alves. 2016.

BIROLI, Flávia. O público e o privado. In: MIGUEL, Luis Felipe; BIROLI, Flávia. Feminismo e política: uma introdução. São Paulo, Boitempo, 2014. p. 31-46. 
BOURDIEU, Pierre. O poder simbólico. Rio de Janeiro: Bertrand Brasil. 2000.

BUTLER, Judith. Problemas de gênero: feminismo e subversão da identidade. Rio de Janeiro: Civilização Brasileira, 2013.

BUTTIGIEG, Joseph A. Subalterno, subalterni. LIGUORI, Guido; VOZA, Pasquale.

Dizionario Gramsciano, 1926-1937. Roma: Carocci Editore, 2009, p. 826-830.

COLLING, Leandro. A igualdade não faz meu gênero - em defesa das políticas das diferenças para o respeito à diversidade sexual e de gênero no Brasil. Contemporânea - Revista de Sociologia da UFSCar. São Carlos, vol. 3, n. 2, jul/dez, 2013, p. 405-427.

DAGNINO, Evelina. Sociedade civil, espaços públicos e a construção democrática no Brasil: limites e possibilidades. São Paulo: Paz e Terra, 2002.

DEL ROIO, Marcos. Gramsci e a emancipação do subalterno. Rev. Sociol. Polít., Curitiba, 29, p. 63-78, nov. 2007.

DOIMO, A. M. A vez e a voz do popular: movimentos sociais e participação política no Brasil pós 70. Rio de Janeiro: RelumeDumará/ANPOCS, 1995.

FACCHINI, Regina; FRANÇA, Isadora Lins. De cores e matizes: sujeitos, conexões e desafios no Movimento LGBT brasileiro. Sexualidad, Salud y Sociedad - Revista Latinoamericana. N. 3, 2009, p. 54-81.

FIGUEIREDO, E. Desfazendo o gênero: a teoria queer de Judith Butler. In: Criação \& Crítica. São Paulo, no 20, 2018, p. 40-55.

FOUCAULT, Michel. História da sexualidade I: a vontade de saber. Rio de Janeiro: Edições Graal, 1988.

GALASTRI, Leandro. Classe sociais e grupos subalternos: distinção teórica e aplicação política. Revista Crítica Marxista, n.39, 2014, p.35-55.

GOHN, Maria da Glória. Movimentos Sociais e Redes de Mobilizações Civis no Brasil Contemporâneo. Petrópolis, RJ: Vozes, 2010.

GÓES, Camila. Repensando a subalternidade: de Antonio Gramsci à teoria pós-colonial. Revista Outubro, n. 26, jul-2016. 2016.

GRAMSCI, Antonio. Cadernos do Cárcere. Rio de Janeiro: Civilização Brasileira, Vol 6, 2002.

GRUPPI, Luciano. O Conceito de Hegemonia em Gramsci. 2 ed, Rio de Janeiro: Graal, 1980.

JOHNSTON, Hank; KLANDERMANS, Bert. Movimentos sociais e cultura. Edição NED Nova Edição. 1995.

MARX, Karl; ENGELS, Friedrich. A ideologia alemã. São Paulo: Boitempo, 2007.

MARX, Karl. A crítica da filosofia do direito de Hegel. São Paulo: Boitempo, 2010.

MEDICI, Rita. Gramsci e o Estado: para uma releitura do problema. Rev. Sociol. Polít., Curitiba, 29, novembro, 2007, p. 31-43. 
MEYER, Dagmar E. Estermann; PETRY, Analídia Rodolpho. Teorias e políticas de gênero: fragmentos históricos e desafíos atuais. Revista Brasileira de Enfermagem, v. 57, n. 1, 2004, p. 13-18.

MIGUEL, Luis Felipe. Desigualdades e democracia: o debate da teoria política. São Paulo: Unesp. 2016.

OKITA, Hiro. Homossexualidade: da opressão à libertação. São Paulo: Sundermann, $2^{a}$ ed., 2015.

PELÚCIO, Larissa. Subalterno quem, cara pálida?: apontamentos às margens sobre póscolonialismos, feminismos e estudos queer. Contemporânea - Revista de Sociologia da UFSCar. n. 2, v. 2, 8, 2012, p. 395-41.

PEREIRA, Cleyton Feitosa. Barreiras à ambição e à representação política da população LGBT no Brasil. Revista Ártemis, Vol. XXIV nº 1; jul-dez, 2017. p. 120-131.

PRADO, Marco Aurélio Máximo; MACHADO, Frederico Viana. Muito além do arco-íris. A constituição de identidades coletivas entre a sociedade civil e o Estado. Annual Review of Critical Psycology. N. 11, 2014.

SÁ, Beatriz Y. P. G.; ARRAZOLA, Laura S. D. O Estado em Gramsci e o debate sobre os direitos sociais dos homosexuais no Brasil. Anais XII CONAGES: Colóquio Nacional Representações de Gênero e Sexualidade. 2015.

SIMÕES, Júlio Assis; FACCHINI, Regina. Do movimento homossexual ao LGBT. São Paulo: Editora Fundação Perseu Abramo, 2009.

SOARES DO BEM, A. A centralidade dos movimentos sociais na articulação entre o Estado e a sociedade brasileira nos séculos XIX e XX. Educ. Soc., Campinas, V. 27, n. 97, set/dez. 2006, p. 1137-1157.

SPIVAK, Gayatri Chakravorty. Pode o subalterno falar? Belo Horizonte: Editora UFMG, 2010.

TEIXEIRA, Ana C. T.; SOUZA, Clóvis H. L.; LIMA, Paula P. F. Arquitetura da Participação no Brasil: Uma Leitura Das Representações Políticas em Espaços Participativos Nacionais. Texto para discussão 1735. Ipea, Rio de Janeiro, 2012. Disponível em:

http://www.ipea.gov.br/participacao/estudos-do-ipea/conferencias2. Acessado em 20/05/2020.

Recebido em: 15/12/2021

Aprovado em: 18/01/2022

Publicado em: 20/01/2022 